\title{
Changes in the Serum Enzyme Levels and Liver Lesions of Broiler Birds Reared Under Different Management Conditions
}

\author{
S.S.H.M.M.L. Senanayake, J.G.S. Ranasinghe ${ }^{1^{*}}$, R. Waduge ${ }^{2}$ \\ K. Nizanantha ${ }^{3}$ and P.A.B.D. Alexander ${ }^{3}$ \\ Postgraduate Institute of Agriculture \\ University of Peradeniya \\ Peradeniya
}

\begin{abstract}
Metabolism of living organisms can be disrupted by the changes in the environment and nutrient intake causing serious diseases such as sudden deaths in broilers. High environmental temperature and ad libitum feeding were suspected as predisposing factors inducing sudden deaths. Our objective was to determine the changes in serum enzyme levels and liver lesions in broiler birds subjected to high temperature and ad libitum feeding. COBB 500 broiler strain was $(n=90)$ divided into three groups including control group $(n=30)$ treatment $1\left(n=30,35^{\circ} \mathrm{C}\right.$ for $12 \mathrm{~h}$ per day) and treatment $2(n=30$, fed ad libitum) and studied from 26 days to 40 days of age. Blood samples $(1.5 \mathrm{ml})$ with 6 replications were withdrawn from wing vein of the birds. The serum Alkaline Phosphatase (ALP), Alanine Transaminase (ALT), Aspartate Aminotransferase (AST), Total Protein and Albumin levels were assessed using commercial kits. Liver tissues of 14, 20, 33 and 38 days old birds from treatment $3\left(33^{\circ} \mathrm{C}\right.$, ad libitum feeding) were fixed, processed and stained with Haemotoxylin and Eosin for histopathological assessment. Data were analyzed using General Linear Model in Minitab 14. The ALP levels were increased with age in control group and treatment 1 group but decreased in the treatment 2 group. The ALT levels were decreased with age in control group and treatment 1 , whereas, increased in the treatment 2 group. AST levels were increased in all three groups. The total Protein levels were increased in treatment 2 but Albumin levels were remained similar throughout the lifespan of birds. Histopathological studies revealed that hepatic necrosis was common in older birds.
\end{abstract}

Keywords: Broiler, histopathology, liver function test

\section{INTRODUCTION}

Broiler birds are of a result of hybrid invention to acquire a higher growth rate. The high nutrient intake to gain more weight causes disruption in animal's metabolism finally resulting in metabolic disorders (Julian, 2005). Metabolic disorders are arisen by a failure either of a hormone or an enzyme system caused by the nutritional, environmental, management and genetic factors. Cardiovascular diseases, ascites and sudden death syndrome are the most important among metabolic disorders since they contribute to a vast proportion of economic loss in the commercial broiler production (Saki and Matin, 2011). Currently, though the

\footnotetext{
Department of Biochemistry, Faculty of Medicine, University of Peradeniya, Sri Lanka

Department of Pathology, Faculty of Medicine, University of Peradeniya, Sri Lanka

3. Department of Farm Animal Production and Health, Faculty of Veterinary Medicine and Animal Science, University of Peradeniya, Sri Lanka

* Corresponding author: Shirani05@yahoo.com
} 
mortality rate is controlled at around $25 \%$, the exact cause of death has not been clearly identified yet from the suspected factors for several metabolic disorders. There were many studies carried out on broiler birds regarding various factors which were predicted to be responsible for disruption of metabolism. So far there were only a few research works have been carried out to investigate the prevailing metabolic syndromes of acute onset. The objectives of this experiment were to understand how the serum enzyme levels and histopathological assessment of liver changes during the life span of broilers under different management practices and different environmental conditions. This study was designed to find the association between predicted etiological factors and disruption of metabolism in broiler birds.

\section{METHODOLOGY}

COBB 500 broiler strain was taken into study from 15 to 40 days of age $(n=90)$ at Veterinary Teaching Farm of Faculty of Veterinary Medicine and Animal Science in the University of Peradeniya which was situated in Udaperadeniya, Sri Lanka (600 m above mean sea level). Ninety birds were divided into three groups namely, control $(n=30)$, treatment $1(n=30)$ and treatment $2(n=30)$. Treatment 1 group was managed at $35^{\circ} \mathrm{C}$ during night $(7.00$ p.m to 7.00 a.m) and kept at room temperature $\left(27^{\circ} \mathrm{C}\right)$ during day time and the treatment 2 group was fed ad libitum with all other factors kept at controlled conditions (room temperature $27^{\circ} \mathrm{C}$, ad libitumwater supply), beginning from the age of 26 days to 40 days. Blood samples were taken with 6 replicates in each group. Sampling was carried out during 8.00 to 9.00 a.m. from the Control group starting from day 15 until 40 days of their age (17.10.2013 to 11.11.2013), every 3 days of interval. Blood samples $(1.5 \mathrm{ml})$ were drawn to $2.5 \mathrm{CC}$ syringes with a 23 gauge needle from wing vein causing minimum stress to the bird. The blood was later collected into labelled serum tubes. Serum was separated by centrifugation at $6000 \mathrm{rpm}$ for 1.30 minutes and serum analysis was carried out immediately. The serum Alkaline Phosphatase (ALP), Alanine Transaminase (ALT) and Aspartate Aminotransferase (AST) were measured using commercial kits (ALP (AP307), AST (AS101) and ALT (AL100) Randox, United Kingdom) and a spectrophotometer. AST and ALT were measured at 546 $\mathrm{nm}$ while ALP measured at $405 \mathrm{~nm}$. The total protein in serum was measured by Biuret test and absorbance was measured at $550 \mathrm{~nm}$ and serum Albumin was measured (AB362 Randox, United Kingdom) at $630 \mathrm{~nm}$.

Another group of broiler birds (Treatment 3 group) reared under general management practice as the control group (controlled feeding and ad libitum water supply) but the environmental temperature was maintained at $33^{\circ} \mathrm{C}$ for 24 hours. The liver tissues from nine birds in treatment 3 group were taken where birds suspected to die due to sudden death syndrome at the ages of 14, 20 and 33 days. The liver samples of four healthy birds were obtained at the age of 38 days. Liver tissues collected at 14,20,33 and 38 days old broiler birds were taken for histopathological assessment. The processed liver tissues in paraffin were cut into $2 \mu \mathrm{m}$ thick sections and stained with Haemotoxylin and Eosin (H \& E). The histological sections were examined and pathological changes were assessed by two independent pathologists under a light microscope $(10 \times 10)$. The tissue samples were obtained from 10.01.2014 to 18.02.2014.

The statistical analysis for biochemical parameters was carried out using Descriptive Statistics, General Linear Model and Pearson Correlation Co-efficient in Minitab 14 software. 


\section{RESULTS AND DISCUSSION}

\section{Biochemical analysis}

The ALP levels of broiler birds in the control group ranged from 2100 to $3300 \pm 204.2 \mathrm{U} / \mathrm{L}$ $($ Mean \pm SEM) at the age of 40 days and the enzyme levels were ranged between 1100 to $1950 \pm 128.2 \mathrm{U} / \mathrm{L}$ at 15 days of age (Figure 1) revealing that the ALP enzyme levels increased with the age of broiler birds. The ALP enzyme activity increased with age and it was higher during the growth of birds from 15 to 25 days of age and reached a plateau from the age of 25 to 40 days (Figure 1). However, the ALP level (2017 - $2250 \mathrm{U} / \mathrm{L})$ in treatment 2 group was significantly decreased $(\mathrm{P}<0.05)$ with the age of broiler birds while the enzyme levels (1840 - $2810 \mathrm{U} / \mathrm{L})$ had slightly increased in the treatment 1 group which was kept at high environmental temperature. The ALP enzyme activity in treatment 2 was varied with the age of birds. It was increased $(\mathrm{P}<0.05)$ around the age of 37 days but decreased again greatly at 40 days of age. The ALP enzyme levels were not changed significantly $(\mathrm{P}>0.05)$ in treatments though the corresponding Mean ALP levels of control, treatment 1 (group with increased temperature) and treatment 2 (group fed ad libitum) are $2369 \pm 686.8 \mathrm{U} / \mathrm{L}, 2504 \pm$ $822.7 \mathrm{U} / \mathrm{L}$ and $2176 \pm 1030 \mathrm{U} / \mathrm{L}$ (Figure 1).

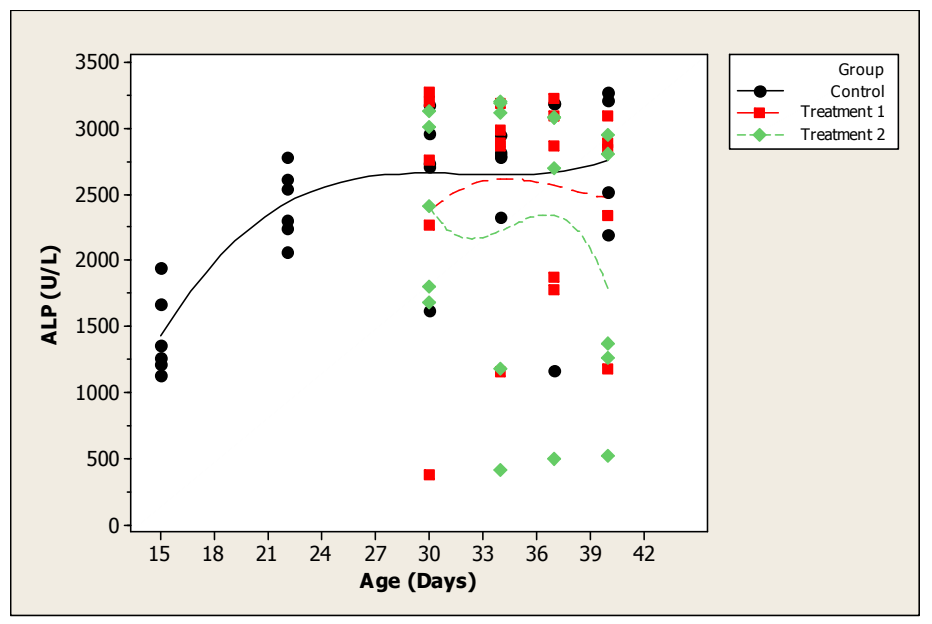

Fig. 1. Change of serum ALP levels in broiler birds with age

The average AST enzyme levels at 15 days of age was ranged in control group between 0.15 to $0.18 \pm 0.0 \mathrm{U} / \mathrm{L}$ and it was increased up to between 0.25 to $0.28 \pm 0.0 \mathrm{U} / \mathrm{L}$ at the age of 40 days in control conditions. Similarly the enzyme levels in both treatment $1(0.19-0.28 \mathrm{U} / \mathrm{L})$ and treatment $2(0.20-0.25 \mathrm{U} / \mathrm{L})$ groups were increased significantly $(\mathrm{P}<0.05)$ with the age of birds and there was a strong positive correlation (Pearson correlation 0.699) between the age of broiler birds and AST enzyme levels. In contrast, the AST enzyme levels had not significantly changed $(\mathrm{P}>0.05)$ with different treatments and the Mean AST levels of control, treatment 1 and treatment 2 groups respectively were $0.20 \pm 0.05,0.22 \pm 0.04$ and $0.22 \pm 0.02 \mathrm{U} / \mathrm{L}$ (Figure 2). 


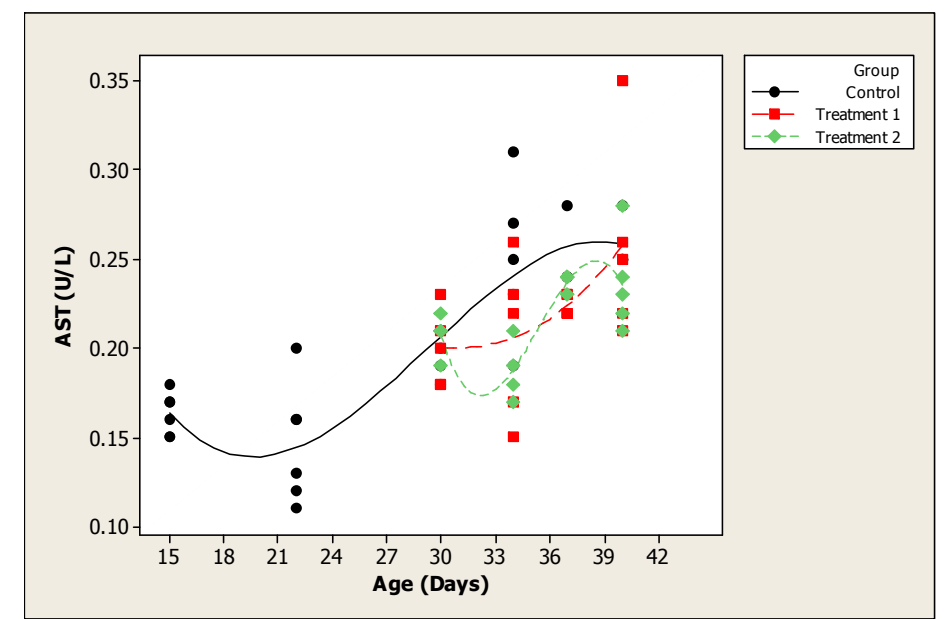

Fig. 2. Variation of serum AST enzyme levels of broiler birds with age

ALT enzyme levels in the control group of broiler birds were between 0.04 and $0.07 \pm 0.0$ $\mathrm{U} / \mathrm{L}$ at 15 days of age and it was between 0.01 and $0.05 \pm 0.0 \mathrm{U} / \mathrm{L}$ at the age of 40 days showing that the ALT enzyme levels were decreased slightly with the age in the control group. The ALT levels in treatment 1 group were decreased $(0.043-0.04 \mathrm{U} / \mathrm{L})$ vastly with the age than in the control group. But the levels of enzyme increased $(0.02-0.05 \mathrm{U} / \mathrm{L})$ in broiler birds of treatment 2 group with age. When considering the change of serum ALT enzyme levels, there was a negative correlation between ALT levels and the age of the bird. The ALT enzyme levels in the control and two treatment groups were decreased significantly $(\mathrm{P}<0.05)$ with age but the enzyme levels in three groups didn't change significantly $(\mathrm{P}>$ $0.05)$ with the given treatments. The mean values of ALT enzyme in control, treatment 1 and treatment 2 groups were $0.044 \pm 0.0,0.041 \pm 0.0$ and $0.037 \pm 0.0 \mathrm{U} / \mathrm{L}$ (Figure 3).

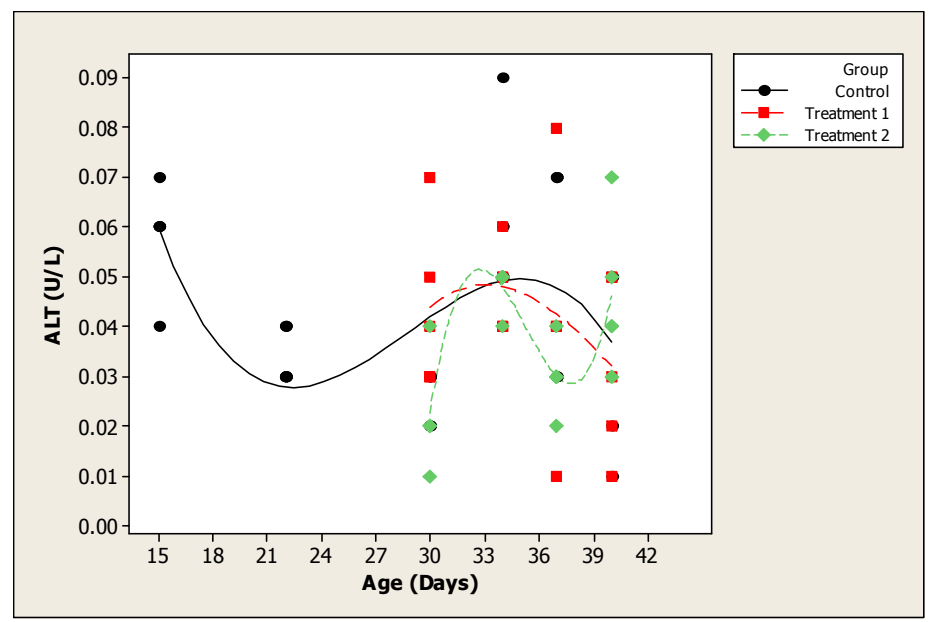

Fig. 3. Serum ALT enzyme levels of broiler birds of different groups during life span 
Calculated values of AST/ALT ratio (Figure 4) were increased with age in both the control $(2.6-17.0)$ and treatment $1(4.3-15.3)$ group and the pattern of ratio increased with age in treatment 1 was greater than in the control group. But the AST/ALT ratio was decreased (8.4 - 5.9) with age in treatment 2 group and the change of enzyme ratio was significant $(P<$ 0.05 ) with age of the birds (Table 1). Although the enzyme ratio was not significantly $(\mathrm{P}>$ 0.05 ) changed, the Mean values of AST/ALT ratio in the control, treatment 1 and treatment 2 groups were $5.9 \pm 4.5,7.3 \pm 6.3$ and $7.1 \pm 4.3$, respectively (Figure 4).

Table 1. Serum AST/ALT enzyme ratio of broiler birds in different groups

\begin{tabular}{lll}
\hline Group & Age in days & $\begin{array}{l}\text { AST:ALT Ratio } \\
\text { (Mean } \pm \text { SEM) }\end{array}$ \\
\hline Control & 15 & $02.9 \pm 0.2$ \\
& 22 & $04.4 \pm 0.3$ \\
& 30 & $07.9 \pm 0.8$ \\
34 & $04.1 \pm 0.2$ \\
& 37 & $06.9 \pm 1.8$ \\
Treatment 1 & 40 & $12.3 \pm 4.7$ \\
& 30 & $05.0 \pm 0.7$ \\
& 34 & $04.3 \pm 0.4$ \\
Treatment 2 & 37 & $09.0 \pm 4.4$ \\
& 40 & $11.4 \pm 3.9$ \\
& 30 & $11.7 \pm 3.3$ \\
& 34 & $03.9 \pm 0.1$ \\
& 37 & $08.4 \pm 1.3$ \\
& 40 & $05.4 \pm 0.5$ \\
\hline
\end{tabular}

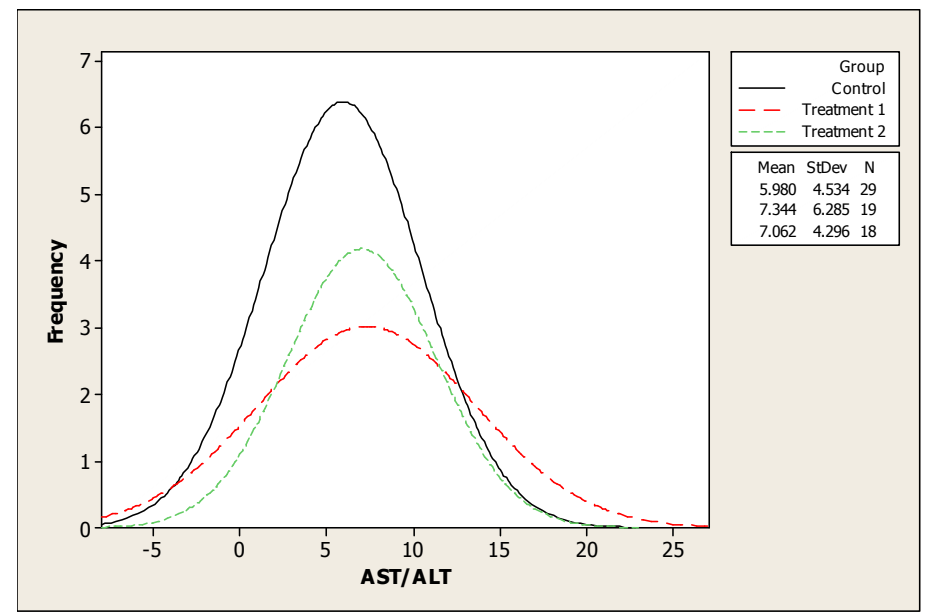

Fig. 4. AST/ALT enzyme ratio of broiler birds in three groups

The serum total Protein content in the control group ranged between 1.5 to $3.6 \pm 0.3 \mathrm{~g} / \mathrm{dL}$ at 15 days of age and it was between 2.7 to $5.8 \pm 0.6 \mathrm{~g} / \mathrm{dL}$ at 40 days of age. There was a slight increase in total proteins in serum of the control birds with their age and the protein content was increased drastically with age in the treatment 2 group which the birds were fed ad 
libitum. But the protein levels were decreased $(2.77-2.48 \mathrm{~g} / \mathrm{dl})$ in the group subjected to an increased temperature (treatment 1) with the birds' age. The total protein content was significantly $(\mathrm{P}<0.05)$ differed with the age in the treatment 2 group and there was a significant $(\mathrm{P}<0.05)$ different in the protein content between the treatment groups. The mean values of total serum protein in control group was $2.9 \pm 0.8 \mathrm{~g} / \mathrm{dL}$ and it was $2.7 \pm 0.9$ $\mathrm{g} / \mathrm{dL}$ in treatment 1 group and $5.9 \pm 2.3 \mathrm{~g} / \mathrm{dL}$ in treatment 2 (Figure 5).

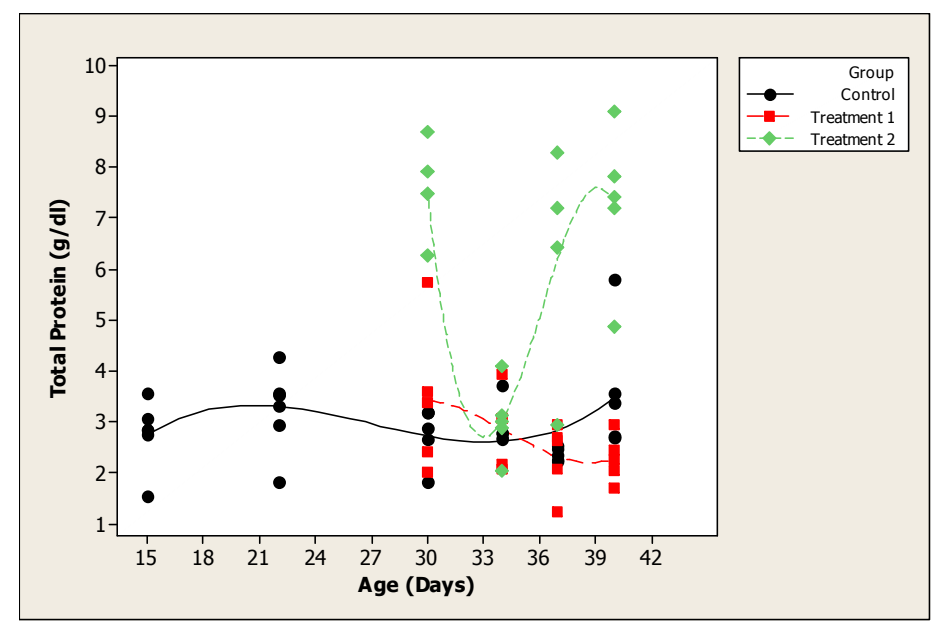

Fig. 5. Total serum protein levels of broiler birds in different groups during their life span

Serum albumin levels of broiler birds in the control conditions varied from 0.5 to $1.4 \pm 0.1$ $\mathrm{g} / \mathrm{dL}$ during their lifetime. There was no correlation between serum albumin levels with the age of birds or with total proteins in serum. The deviation of albumin levels with age was not significant $(\mathrm{P}>0.05)$ as well as with each treatment group of broiler birds. The mean albumin levels were also nearly similar in birds of control, treatment $1(0.54-1.05 \mathrm{~g} / \mathrm{dl})$ and treatment $2(0.54-1.03 \mathrm{~g} / \mathrm{dl})$ groups (Figure 6).

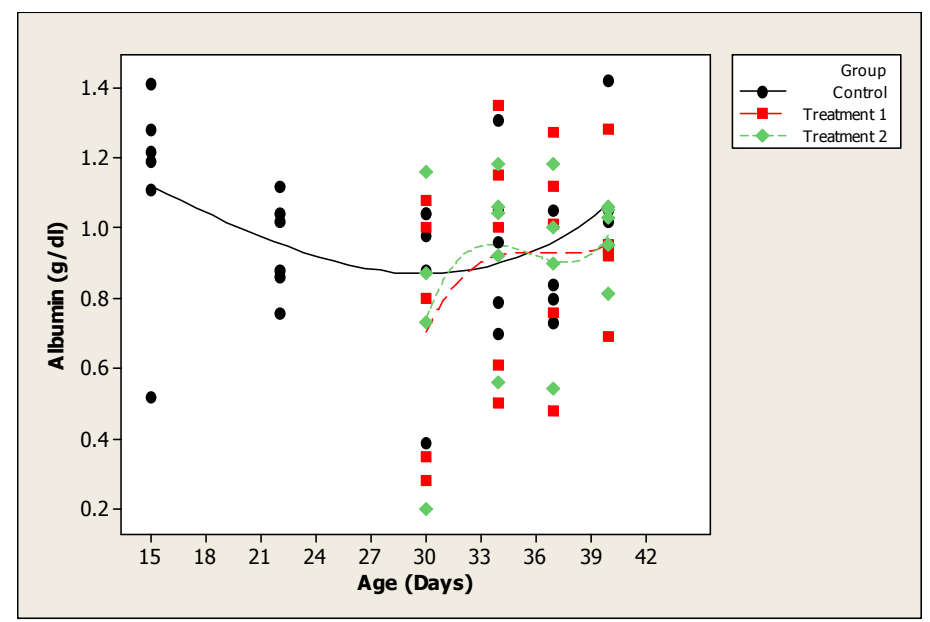

Fig.6. Serum albumin levels of broiler birds of different groups during their life time 
The total globulin level ranged from 0.1 to $0.4 \pm 0.1 \mathrm{~g} / \mathrm{dL}$ at 15 days of age and at 40 days of age it ranged from 3.8 to $8.0 \pm 0.7 \mathrm{~g} / \mathrm{dL}$ (Figure 7). The globulin levels were significantly ( $\mathrm{P}$ $<0.05)$ differed with the age of the broiler birds. Also the amount of serum globulin was significantly $(\mathrm{P}<0.05)$ changed with each broiler groups. There was a strong positive correlation (0.99) of globulin with total protein. The globulin levels in the control group $(1.49-3.17 \mathrm{~g} / \mathrm{dl})$ and the treatment $2(6.45-6.99 \mathrm{~g} / \mathrm{dl})$ group were increased with the birds' age and the globulin levels of treatment 2 group was higher than the control group. But the globulin in treatment 1 group which was given a higher environmental temperature was decreased with the birds' age. The mean values of globulin in control group and in treatment 1 group were nearly similar, which were $1.96 \pm 0.7$ and $1.83 \pm 0.9 \mathrm{~g} / \mathrm{dL}$ respectively whereas the mean of treatment 2 group was $5.03 \pm 2.4 \mathrm{~g} / \mathrm{dL}$ (Figure 7).

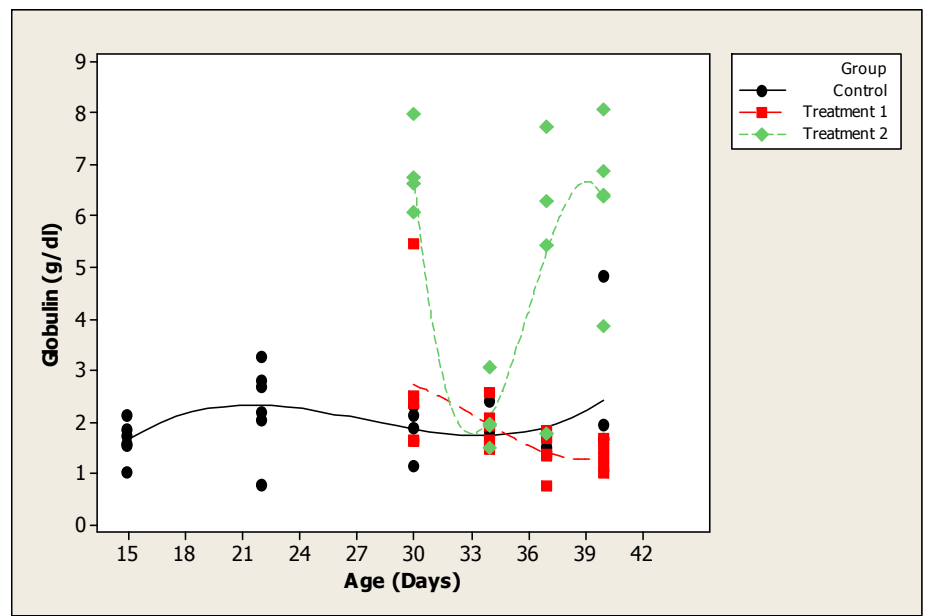

Fig. 7. Serum globulin levels of broiler birds of different groups during their life time

\section{Histopathological assay}

The histopathological changes were significant. There were areas of sinusoidal congestion. Increased sinusoidal congestion in some liver samples was observed in the deceased birds with aging but it was mildly present in healthy birds. Areas showing focal lytic necrosis and multifocal necrosis were identified. The intensity of multifocal necrosis was remarkably increased with respect to the age in the deceased birds. Most importantly multifocal necrosis was present at a moderate amount in the healthy birds which were slaughtered. Ballooning degeneration were identified in some birds at the age of 14 and 20 days as well as in healthy birds at 38 days. Heavy neutrophilic infiltrations of the hepatocytes were noted in aged broiler birds. The liver cell changes in broiler birds are presented in Table 2 . 
Table 2. Liver cell changes in broiler birds

\begin{tabular}{cccc}
\hline $\begin{array}{c}\text { Bird's age in } \\
\text { days }\end{array}$ & $\begin{array}{c}\text { Sinusoidal } \\
\text { Congestion }\end{array}$ & $\begin{array}{c}\text { Ballooning } \\
\text { Degeneration }\end{array}$ & $\begin{array}{c}\text { Multifocal } \\
\text { Necrosis }\end{array}$ \\
\hline 14 & Present & Absent & $\begin{array}{c}\text { Present } \\
\text { Moderately present } \\
\text { Present }\end{array}$ \\
14 & Present & Absent & Present \\
14 & Present & Absent & Moderately present \\
20 & Moderately present & Absent & Present \\
20 & Present & Absent & Absent \\
20 & Present & Present & Moderately present \\
20 & Present & Absent & Markedly present \\
& Present & Absent & Markedly present \\
33 & Markedly present & Absent & Moderately present \\
33 & Present & Present & Moderately present \\
& Absent & Absent & Moderately present \\
38 & Present & Present & Moderately present \\
38 & Present & & \\
38 & & &
\end{tabular}

The H \& E stained images of liver tissues taken from the birds which died suddenly and healthy birds at slaughter are as shown below.

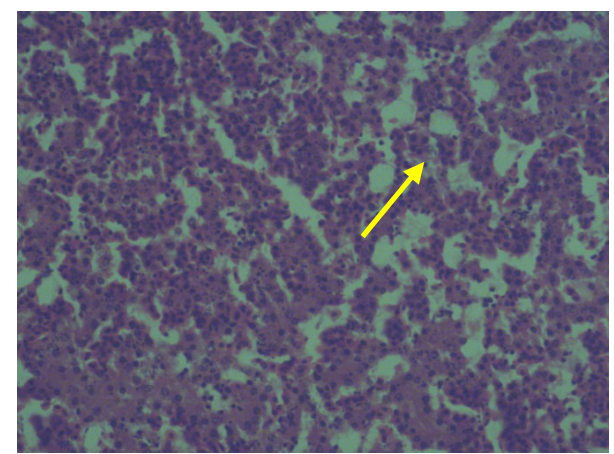

Fig. 8. H \& E (10x10)

Fourteen days old broiler bird died suddenly in treatment 3 . The sinusoids were markedly congested (arrow) and the hepatocytes were unremarkable.

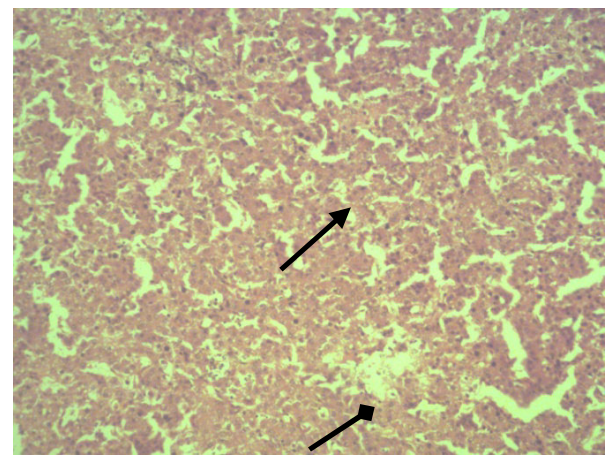

Fig. 9. H \& E (10x10)

Twenty days old broiler bird died suddenly in treatment 3 . The sinusoids were congested (arrow) and there were multifocal hepatocyte necrosis (diamond arrow). 


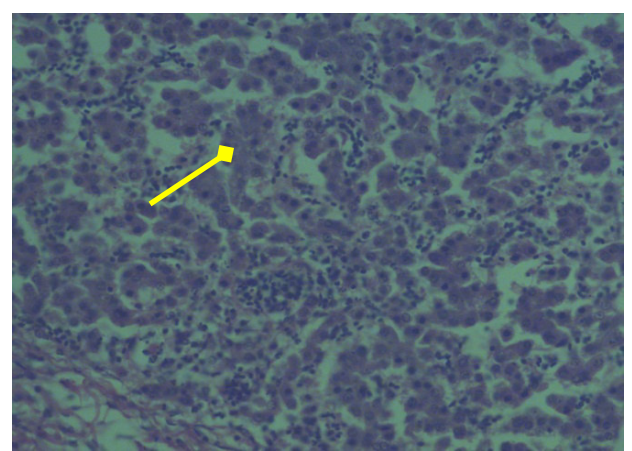

Fig. 10.H \& E (10x10)

Thirty three days old broiler bird died suddenly in treatment 3 . The sinusoids were congested with marked hepatocyte necrosis (arrow).

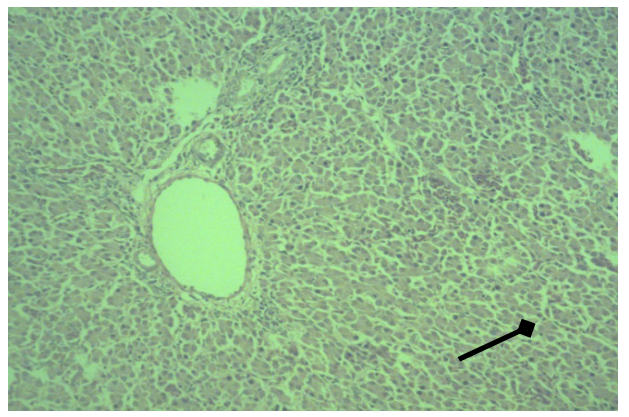

Fig. 12. H \& E (Scanner view)

Slaughtered broiler bird at thirty eight days of age in treatment 3 . The vessels were mildly congested.

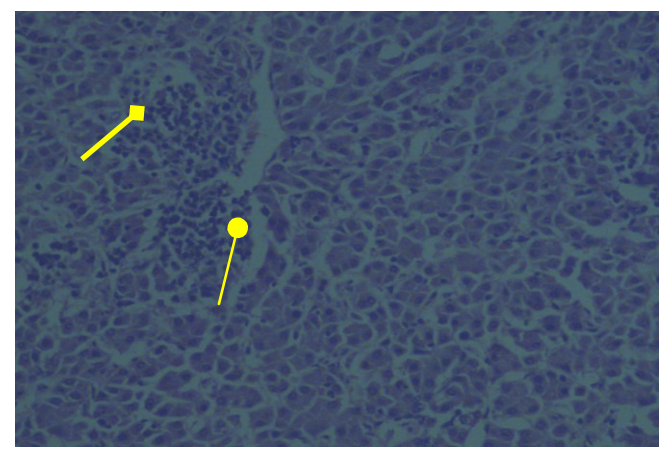

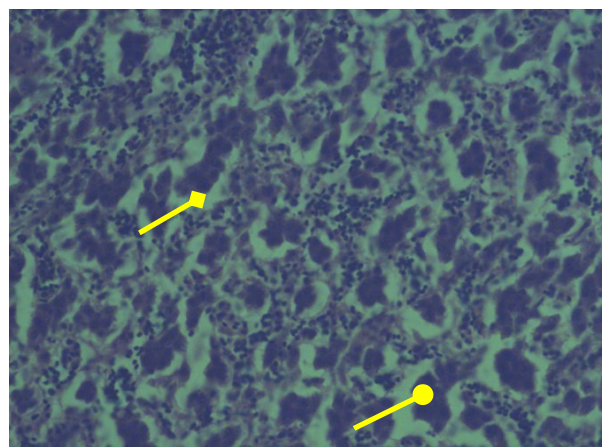

Fig. 11. H \& E (10x10)

Thirty three days old broiler bird died suddenly in treatment 3 . The sinusoids were severely congested with hepatocyte necrosis.

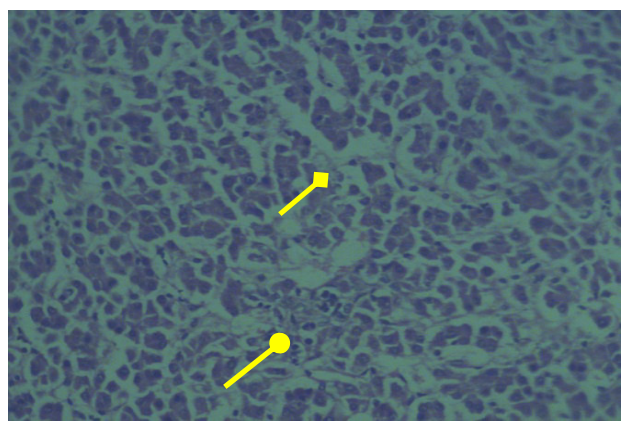

Fig. 13. H \& E (10x10)

Slaughtered broiler bird at thirty eight days of age in treatment 3. Mild degenerations were presented.
Arrow
- Congested sinusoids
Diamond arrow
- Multifocal necrosis patches
Oval arrow

Fig. 14. H \& E (10x10)

Slaughtered broiler bird at thirty eight days of age in treatment 3 . The sinusoids were mildly congested. 
Analysis of serum enzyme activities is an important application in diagnosis of avian diseases, but the enzymes having wide ranges of activities make difficult to interpret the results (McDaniel et al., 1964). ALP is an enzyme responsible for dephosphorylation of a substrate therefore it is produced in all types of tissues in the body, but it getsactivated in alkaline $\mathrm{pH}$. Therefore, elevated levels of ALP can be mostly seen in liver damages. In this study, elevated ALP levels were observed in control group which might be due to the production of ALP as a by-product in active bone formation (Farley and Baylink, 1986). The decrease of ALP in the treatment 2 group in which the birds were fed ad libitum might occur due to several reasons. It has been reported that intake of vitamin D closely link with the serum ALP levels (Kaslow, 2013). In this study, since in the treatment 1 group with high environmental temperature had drastically reduced the feed intake, the increased ALP could be due to lack of Vitamin D. Further, improper nutrition may indirectly caused the degeneration of the liver.

ALT enzyme is found in highest amount in liver and is used to identify acute liver failures (Orlewick and Vovchuk, 2012) as the enzyme is released into the serum immediately after a hepatocellular damage. But in this study, the ALT levels in control group and the group with increased temperature (Treatment 1) were slightly decreased with age. The ALT levels in the treatment 1 group decreased more rapidly than the control group. The high temperature may cause a gross liver failure which may result in lowering of ALT (Wasserman, 2013) as seen in the treatment group 1. The treatment 2 group broilers with ad libitum feeding had a slight increase in ALT levels with the age and this can be due to the metabolic demand for the liver with high feed intake (Schindhelm et al., 2006).This is further confirmed by degenerative changes in the liver as shown in Figure 9.

All the 3 groups had general elevation of serum AST. There is enough evidence that broilers show inflammatory changes in the liver through their life (Singh et al., 2011). In this study, the increased AST in the control group indicates that the rapid growth rate of the COBB 500 broiler could be the cause for general liver lesions. The increased level of AST might be lowered due to lessened growth rate (15\% at 37 days) caused by reduced food intake in the group with increased temperature.

The increased AST/ALT ratio in the control group and treatment 1(increased temperature) group indicates that increased heat may cause chronic liver damage in fast growing broilers (Dudley et al., 1982) and this might relate with the occurrence of sudden death syndrome (SDS) when compared with the enzyme levels of dead broilers from sudden death syndrome in other studies (Qujeq and Aliakbarpour, 2005). As clearly shown in the present study, the effect of feed intake on the functions of major organs such as liver and heart may lead to SDS.

The total proteins and globulins were changed in proportional to the feed intake in all groups. This was clearly shown in the treatment 1 group where the total protein and globulin content were decreased with the age of the broiler birds (Figures 5 and 7). As observed in the study, the feed intake in the treated group (increased temperature) was low compared with the control group.

Among the histopathological changes of liver, the hepatic necrosis was more evident in older age groups of birds subjected to either sudden death or slaughter. More importantly presence of multifocal necrosis in liver tissues which were obtained from healthy birds at slaughter describes that the birds reared under high temperature indirectly affects the liver tissue. This study may help in predicting the effect of environmental temperature and food supply in the 
management of broiler birds. The results may also help to understand the effect of environment temperature as a stress factor affecting the nutritional status of broiler birds. Further studies with respect to the dietary management are needed to fully understand the other causes leading to metabolic disturbances and SDS.

\section{CONCLUSION}

The increased temperature reduced the feed intake of the treated group 1 hence the serum total protein and globulin levels were decreased. But the albumin levels weren't much changed due to the homeostatic regulation within the systems. Comparatively the ad libitum feeding elevated the levels of total protein and globulin. High nutrient intake resulted in increased serum AST and ALT levels. This is due to the high metabolic demand by the liver which led to the hepatocellular degeneration. The ALP and AST levels of normal broiler birds increased as they aged indicating that the fast growth rate was responsible for the hepatic damage.

\section{ACKNOWLEDGMENTS}

Firstly we are grateful to the PGIS, University of Peradeniya for giving us this research opportunity. Then to the technical assistance given by Dr. W. M. T. D. Rathnakumara, Mr. J. M. N. S. Navarathne, Mrs. T. A. D. N. Talpearachchi, Mrs. V. P. P. Jayapani and Mrs. T. R. D. S. K. Tennakoon and Dr. M. L. A. N. R. Deepani for the statistical assistance. We heartily appreciate the kind support given by the staff of Department of Farm Animal Production and Health of Faculty of Veterinary Medicine and Animal Science and Department of Biochemistry and Department of Pathology of Faculty of Medicine of University of Peradeniya.

\section{REFERENCES}

Aengwanich, W. and Simaraks, S. (2004). Pathology of heart, lung, liver and kidney in broilers under chronic heat stress. Songklanakarin Journal of Science and Technology. 26(3), 417-424.

Al-Sultan, S.I. and Gameel, A.A. (2004). Histopathological changes in the livers of broiler chicken supplemented with Turmeric (Curcuma longa). International Journal of Poultry Science. 3(5), 333-336.

Kaslow, J.E. (2013). Alkaline phosphatase [on line]. [Accessed on 07.10.2013]. Available at http://www.drkaslow.com/html/alkaline_phosphatase.html

Dudley, R.E., Svoboda, D.J. and Klaassen, C. D. (1982). Acute exposure to cadmium causes severe liver injury in rats. Toxicology and Applied Pharmacology. 65(2), 302-313.

Farley, J.R. and Baylink, D.J. (1986). Skeletal alkaline phosphatase activity as a bone formation index in vitro. Metabolism. 35(6), 563-571.

Julian, R.J. (2005). Production and growth related disorders and other metabolic diseases of poultry - a review. The Veterinary Journal. 169(3), 350-369. 
McDaniel, L.S. Dempsey, H.A. and Chute, H.L. (1964). Enzyme levels in birds. Maine Agriculture Experiment Station Technical Bullletin. 8

Orlewick, M.S. and Vovchuk, E. (2012). Alanine Aminotransferase [on line]. [Accessed on 14.11.2013]. Available at http://emedicine.medscape.com/article/2087247-overview

Qujec, D and Aliakbarpour, H. R. (2005). Serum Activities of Enzymes in Broiler Chickens that Died from Sudden Death Syndrome. Pakistan Journal of Biological Sciences. 8(8), 1078 $-1080$.

Saki, A.A. and Matin, H.R.H. (2011). Does nutrition help to alleviate sudden death syndrome in broiler chicken? An overview. Global Veterinaria. 6(3), 262-268.

Schindhelm, R.K., Diamant, M., Dekker, J.M., Tushuizen, M.E., Teerlink, T. and Heine, R. J. (2006). Alanine aminotransferase as a marker of non-alcoholic fatty liver disease in relation to type 2 diabates mellitus and cardiovascular disease. Diabates/ Metabolosm Research and Reviews. 22(6), 437-443.

Siddiqui, M.F M.F., Patil, M.S., Khan, K.M. and Khan, L. A. (2009). Sudden death syndrome - An overview. Veterinary World. 2(11), 444-447.

Singh, D., and R. S. Gupta. "Hepatoprotective activity of methanol extract of Tecomellaundulata against alcohol and paracetamol induced hepatotoxicity in rats." Life Sci Med Res 26 (2011): 1-8.

Wasserman, R. (2013). Low levels of Alanine Aminotransferase [on line]. [Accessed on 21.10.2013]. Available at http://www.livestrong.com/article/303552-low-levels-of-alanineaminotransferase/ 